\title{
BMJ Open Attitudes and views on healthy lifestyle interventions for the prevention of dementia and cardiovascular disease among older people with low socioeconomic status: a qualitative study in the Netherlands
}

Esmé Eggink (1) , ${ }^{1}$ Melanie Hafdi, ${ }^{2}$ Marieke P Hoevenaar-Blom, ${ }^{3}$ Edo Richard,${ }^{3,4}$ Eric $\mathrm{P}$ Moll van Charante, ${ }^{1,3}$ on behalf of the PRODEMOS-consortium

To cite: Eggink E, Hafdi M, Hoevenaar-Blom MP, et al. Attitudes and views on healthy lifestyle interventions for the prevention of dementia and cardiovascular disease among older people with low socioeconomic status: a qualitative study in the Netherlands. BMJ Open 2022;12:e055984. doi:10.1136/ bmjopen-2021-055984

- Prepublication history and additional supplemental material for this paper are available online. To view these files, please visit the journal online (http://dx.doi.org/10.1136/ bmjopen-2021-055984).

Received 04 0ctober 2021 Accepted 01 February 2022

Check for updates

(c) Author(s) (or their employer(s)) 2022. Re-use permitted under CC BY-NC. No commercial re-use. See rights and permissions. Published by BMJ.

For numbered affiliations see end of article.

Correspondence to Professor Eric P Moll van Charante;

e.p.mollvancharante@ amsterdamumc.nl

\section{ABSTRACT}

Objectives Individuals with a low socioeconomic status (SES) have an increased risk of cardiovascular disease (CVD) and dementia, partly due to the high prevalence of unhealthy behaviours in this population. Interventions targeting lifestyle-related risk factors can potentially delay or prevent CVD and dementia onset. In this study, we explore the attitudes, experiences and views of low SES older adults on healthy lifestyles for the prevention of CVD and dementia. We also aim to study the potential role for coach-supported mobile health (mHealth) use, facilitating the development of the Prevention of Dementia using Mobile Phone Applications intervention.

Design We performed semi-structured interviews and used thematic analysis to analyse the data.

Setting Recruitment through multiple general practices in the Netherlands.

Participants Dutch non-demented adults aged $\geq 55$, at increased risk of dementia, who possess a smartphone. Participants were purposively sampled on age, sex and history of CVD and diabetes.

Results Between May 2018 and June 2019, we performed 19 interviews. Five main themes were: (1) participants perceived little influence on their future health (2) the sacrifices of healthy lifestyles outweighed the potential benefits, (3) physical complaints or disease could prompt behaviour change, (4) participants perceived they had limited self-efficacy to change their behaviour and (5) the social network had an important role in behaviour change. Needs regarding mHealth support were an easyto-use smartphone application with trustworthy health information, which is provided in a non-obligatory way. Conclusions Low SES older adults may benefit from lifestyle interventions that aim to improve self-efficacy levels by (remote) human support. Appropriateness and attractiveness of such interventions may increase when taking into account the participant's own autonomy, and when emphasising the direct gains of lifestyle changes for daily life. Moreover, involving the social network may be a valuable approach when developing lifestyle interventions for low SES older adults.
Strengths and limitations of this study

- Through purposive sampling on age, living situation and cardiovascular history in this hard-to-reach population, we were able to provide an overview of the potential attitudes, experiences and views of Dutch low socioeconomic status (SES) older adults on healthy lifestyles to prevent cardiovascular disease and dementia.

- The lack of an advanced prototype prohibited an in-depth exploration of specific needs and preferences regarding the functionalities and layout of the Prevention of Dementia using Mobile Phone Applications mobile health intervention.

- Since general practitioners were specifically asked to invite low SES individuals, this may have led to an over-representation of the lowest SES levels, potentially overestimating lack of self-confidence and self-efficacy of this group.

Trial registration number PRODEMOS trial, ISRCTN15986016; Pre-results.

\section{INTRODUCTION}

Individuals with a low socioeconomic status (SES) have a substantially increased risk of cardiovascular disease (CVD) $)^{1}$ and dementia ${ }^{2}$ compared with their high SES counterparts. One of the explanations for this difference is the high prevalence of unhealthy behaviours among low SES individuals, including smoking, unhealthy diet and insufficient physical activity. ${ }^{34}$ This suggests that lifestyle interventions targeting cardiovascular risk factors may have particular potential to delay or prevent CVD and dementia onset in low SES populations. 
Digital health-supported lifestyle programmes are emergent strategies for the delivery of interventions to hard-toreach populations, given the rapidly increasing availability of internet around the world.$^{5}$ Previously, a meta-analysis suggested that the cardiovascular risk profile of middleaged and older people could be improved by web-based lifestyle interventions, especially when combined with human support. ${ }^{6}$ More recently, the Healthy Ageing Through Internet Counselling in the Elderly (HATICE) trial showed that a coach-supported digital lifestyle intervention can improve the cardiovascular risk profile of older European adults. ${ }^{7}$

Building on experiences gained from the HATICE trial, the Prevention of Dementia using Mobile Phone Applications (PRODEMOS) trial will assess the effectiveness and implementation of a coach-supported mobile health (mHealth) platform, facilitating self-management of risk factors to reduce dementia risk in older people with a low SES background in the UK. ${ }^{8}$ Effectively reaching low SES populations is challenging, as they generally tend to benefit less ${ }^{910}$ and are more likely to drop out ${ }^{11}$ of intervention studies. Also, barriers for healthy behaviours and needs regarding lifestyle support appear to differ from those with high SES. ${ }^{12-14}$ Therefore, tailoring of our lifestyle intervention to their needs and preferences is crucial to effectively reach and engage low SES participants. ${ }^{15-17}$

In the current qualitative study, we aim to explore the attitudes, experiences and views of Dutch low SES older adults on healthy lifestyles for the prevention of dementia and CVD. We also aim to study the potential role for coach-supported mHealth use, facilitating development and further adaptation of the PRODEMOS mHealth intervention.

\section{METHODS}

\section{Participants and setting}

Participants were recruited through six general practices in the Netherlands, covering both rural and urban areas. Eligibility criteria were age $\geq 55$ years, a low SES background, smartphone possession and increased risk of dementia (defined as the presence of $\geq 2$ dementia risk factors, that is, history of CVD, diabetes, hypertension, overweight, dyslipidaemia, depression, insufficient physical activity and current smoking). Participants were purposively sampled on age, sex, living situation and history of CVD and diabetes. Overall eligibility was assessed by the general practitioner and validated through a screening phone call by one of the researchers. We verified the participants' educational level as a proxy for SES and only included those with an International Standard Classification of Education level of $\leq 2$ (comparable with primary school or lower secondary education as highest completed educational level). In total, 19 out of 27 eligible individuals were willing to participate in the study. Written informed consent was obtained before the start of each interview for all participants.

\section{Data collection}

Between May 2018 and June 2019, three researchers (EE, $\mathrm{MH}$ and MPH-B) performed semi-structured interviews. The interviewers had no professional or other type of relationship with the participants. The professional backgrounds of the researchers (ie, medical doctor (EE, MH) and dietician (MPH-B)) were not actively mentioned, to reduce the risk of socially desirable answers.

The interview guide (online supplemental appendix 1) comprised questions about experiences and attitudes regarding lifestyle behaviour change in relation to dementia and CVD prevention, and about needs for and views on the potential role for mHealth. When deemed necessary, we iteratively adapted the guide based on experiences during the interviews. Examples of such adjustments are adding questions on the role of religion and financial resources in disease prevention.

Interviews took place at the participants' homes, to avoid potential undesirable effects of a medical setting on participants' response. Interviews lasted approximately 45 min (range 25-60 min), were audiotaped and transcribed verbatim. Transcripts were enriched with field notes taken during the interviews. Participants were offered the opportunity to contact the research team in a later stage if they had further remarks or questions regarding the study, or if they wanted to withdraw participation. According to the Dutch law, the study was not required to undergo review by a Medical Research Ethics Committee.

\section{Coding and analysis}

Data were thematically analysed following the six phases as described by Braun and Clarke. ${ }^{18}$ The first two steps of analysis were concurrent with the interviews.

1. All researchers (EE, MH, MPH-B and EPMvC) familiarised themselves with the data by thoroughly reading the transcripts. The researchers involved in initial coding (EE, MH and MPH-B) additionally listened to the audiotapes of the interviews.

2. Initial coding was done using MaxQDA in sets of 2-3 interviews. Each interview was independently coded by EE and by either MH or MPH-B. Initial codes of each set of interviews were compared and discussed until any disagreements were resolved, resulting in a new set of codes. We used a data-driven approach, coding the content of the entire dataset.

3. After reaching data saturation and finishing initial coding, EE, MH and MPH-B independently searched for potential themes by combining codes in MaxQDA. In a face-to-face meeting, all printed codes were visually mapped and organised into themes. In a face-to-face discussion with EPMvC, these themes and their potential interrelationships were discussed.

4. EE and EPMvC reviewed the candidate themes and subthemes. Some themes were merged, whereas other themes were refined or split into multiple themes. EE reread all initial codes, to judge whether the themes were a good representation of the data. 
Table 1 Sociodemographic characteristics and medical history of included participants

\begin{tabular}{|c|c|c|}
\hline Characteristic & & $\mathrm{N}=19$ \\
\hline Age (year) & Median (range) & $67(55-77)$ \\
\hline Sex (female) & N (\%) & $8(42)$ \\
\hline Born in the Netherlands (yes) & $N(\%)$ & $17(89)$ \\
\hline History of CVD (yes) & $\mathrm{N}(\%)$ & $12(63)$ \\
\hline History of diabetes (yes) & $\mathrm{N}(\%)$ & $11(58)$ \\
\hline Living situation & $\mathrm{N}(\%)$ & \\
\hline With partner & & $11(58)$ \\
\hline With other & & $1(5)$ \\
\hline Alone & & $7(37)$ \\
\hline
\end{tabular}

CVD, cardiovascular disease.

5. Narratives for each theme were written by EE, describing the themes and subthemes. MH, MPH-B and EP$\mathrm{MvC}$ reviewed the narratives, and made adaptations to the names and arrangement of the themes where deemed appropriate.

6. Narratives were enriched by illustrative examples, which were selected by EE, MH and MPH-B, and reviewed by EPMvC.

\section{Patient and public involvement}

Patients and/or the public were not involved in the design or conduct of this study.

\section{RESULTS}

We performed 19 semi-structured interviews. Participants were aged 55-77 years. Twelve participants had a history of CVD. Demographics of participants are presented in table 1.

In line with our research question, we will present the results in two sections. Part I describes the attitudes, experiences and views regarding healthy lifestyles for prevention of CVD and dementia. We identified five key themes: (1) little perceived influence on future health, (2) sacrifices outweigh the potential benefits, (3) physical complaints or disease can prompt behaviour change, (4) limited self-efficacy on behaviour change and (5) important role for the social network. In part II, we will address the needs and views regarding lifestyle support and the potential role of coach-supported mHealth.

\section{Part I: attitudes, experiences and views regarding healthy lifestyles for disease prevention \\ Little perceived influence on future health}

Many participants felt that they had little or no influence on their future health or disease onset, because it is largely predestined. Health and disease were often seen as a matter of (bad) luck or as something that is decided by a higher spirit or genetic predisposition, rather than a risk that can be affected by choices in lifestyle behaviour.

I do my best in life and I try to be positive and it's all in the Lord's hands. [...] And who knows, tomorrow
I cross a road without seeing a car approaching, and then you're gone too. [...] Living a healthier lifestyle to avoid diseases, I don't know about that.

Moreover, some participants did not recognise a potential effect of (un)healthy behaviours on disease risk, based on previous experiences. Participants often related to anecdotes of relatives or friends who used to have a healthy lifestyle but eventually got ill, or people who had become very old in spite of their unhealthy behaviours, to question the assumed relation between healthy lifestyles and favourable health outcomes.

I see people who say: 'If you smoke, you'll get lung cancer.' Blah blah blah. I mean, my grandfather smoked his whole life. He lived to 87 years old. He didn't die from lung cancer.

\section{Sacrifices outweigh potential benefits}

Many participants stated that making sacrifices, such as depriving oneself from tasty foods and alcohol, or engaging in physical activities that were not deemed enjoyable, as disproportionate to the potential benefits of such healthy behaviours. Participants often referred to the potential benefit of healthy behaviours as 'perhaps living a year or two longer', without considering potential positive effects on the quality of life. Especially with ageing, having a pleasant life in the present seemed to be more meaningful than potential future gains from a healthy lifestyle.

But I can't bring myself to go to the gym and work up a sweat for an hour there.

And we're all gonna go at some point anyway, so at that point I'd rather be able to say I had a comfortable life than a longer one.

\section{Physical complaints or disease can prompt behaviour change}

In retrospect, many participants found it difficult to pinpoint what had made them initiate working on a healthy lifestyle, but often they referred to a specific moment in time, when something 'clicked' for them, causing them to flip a switch.

-And how did you manage to stick with it [quit smoking]?

[...] someone flipped a little switch in me. If you don't want to, it's not gonna happen. Then nothing will work.

\section{-But what was that switch?}

I don't know. But yeah, suddenly you really want it. And you're fully behind it [...]You have to flip that little switch.

For some participants, becoming ill, such as getting a CVD or diabetes, was the spark that set off behaviour change, to prevent further deterioration or relapse of the disease. This seemed to be especially the case for smoking. Sometimes, lifestyle advice from healthcare 
workers shortly after diagnosis was a trigger for such behaviour change.

I smoked like a chimney. And never touched another cigarette since that day [heart attack].

Yeah, because at first the surgeon who cut open my groin, she just said [...] "Are you ever gonna be done with that stupid smoking habit?"' I'll never forget that. [...] she saw right away that I was a pretty heavy smoker. [...] At that point I said to myself: "I'm done [smoking]".

For other participants, physical discomfort caused by unhealthy behaviours rather than a formal disease was an incentive to change. Examples are breathing problems caused by smoking, or being unable to tie shoelaces due to obesity.

[... I can hardly tie my shoelaces. And look, that annoys the hell out of me. But now I've been wearing slippers for 3 months [...] so now I'm not annoyed. And soon I'm gonna have to wear my shoes again, and maybe that will cause to flip a switch.

I don't quit smoking for lung cancer or anything. [I quit] for myself. For my [takes a deep breath] wheezing. And my [coughs loudly] during the night

\section{Limited self-efficacy on behaviour change}

\section{Breaking with habits is a daunting challenge}

For some participants changing behaviour felt like a major hurdle, especially when unhealthy lifestyles had become a long-standing habit.

Well, look, at some point it just turned into a habit, the smoking. [...]You just need something in your mouth.

Some participants said that they were aware that they should change long-lasting habits, and knew how they should change, but found it hard to put knowledge into action.

We know bloody well that all that fried fish isn't good for me, actually. [...] And we also know well enough that we should be eating healthy fish. It shouldn't be fried. [...] No, [it's] not about knowing better, it's about living habits.

\section{Disappointing results have a demotivating effect}

Participants who had previously initiated behaviour change mentioned that their progress declined after some time. For many of them, this had a demotivating effect on their (future) attempts to change their lifestyle.

At some point [...] it [weight] uhh kind of stays the same. And it won't go down any more. And then, that's the moment for me [...] it falters.
Important role for the social network Importance of maintaining autonomy

Some participants took issue with others meddling with their lifestyle behaviour. They stressed that unsolicited lifestyle advice could even have a counterproductive effect on their motivation to change. Some people preferred advice from people in the inner circle, such as a partner, to advice from people who are less familiar, such as healthcare professionals.

I ain't letting anyone tell me what to do. [...] If they're gonna tell me: "you have to ..." then I'm gonna do the opposite.

My coach is on the other side of the [kitchen] table. Really, I'm serious. [...] She [spouse] is the only one who's advice I'll take.

\section{Family and close friends can prompt behaviour change}

Some participants mentioned that their attempts to change their lifestyle behaviour were triggered by people from their inner social circle. In some cases, negative feedback by close family members caused feelings of embarrassment, sparking efforts to quit smoking or lose weight.

\section{-And do you remember why you suddenly thought: I need to lose weight?}

My daughter. [...] I noticed that at some point she started [...] walking a few metres behind me. And that she was kind of like, I don't wanna become like my mother. And then I was like, I don't want that.

Having a healthy lifestyle is easier when done together with peers For many participants, living closely together with peers following healthy lifestyles or aiming to improve them, made it easier to adopt similar behaviours.

\section{-Were there things that helped you abstain?}

The home front really. No smoking at home.

Some participants tried to make changes to their lifestyle by changing their behaviour together with friends or family. Such peers could provide increased incentive to stick to the intended behaviour.

Well, I happened to have a buddy. [...] So I'd meet them at the gym. And then uh, "Did you smoke?" "No". "No, me neither". You know. [...] And then you can deal with it.

Especially in the case of physical activity, participants looked for peers who had approximately the same age and had similar impairments or goals. A safe environment with mutual understanding for each other's health situation was deemed imperative to successfully involve in physical exercise together.

I do feel very [...] safe. [...] I'm not good at running. And uhh, when you're like: "Phew" and you sit down for a moment. Nobody will be like: "Hey, come on!!" 
Part II: potential role for coach-supported mHealth use

We explored the potential added value of a coachsupported mHealth intervention to facilitate lifestyle behaviour change, as part of the development of the PRODEMOS platform.

\section{Professional lifestyle support}

For some participants, previous lifestyle coaching from a healthcare professional had made it easier to change their behaviour, due to the added impetus to achieve lifestyle goals.

\section{-And that coach at the time, from the doctor ... how was she able to guide you in the quitting process?}

Yeah ... that's what a big stick does. Because you have to show up like every week. [...] I mean, then you can't be like: I smoked.

Some participants indicated that healthcare professionals should be careful when offering lifestyle advice. Language used should be not too coercive, but rather friendly and open to the participant's own views.

Don't start telling me what to do or what not to do [...]

\section{-And what would the ideal approach look like?}

That you give people ideas: "Have you considered this?" Or: "Have you tried that?"

Several participants mentioned that consistent and trustworthy health information is an important facilitator for behaviour change. Especially in the case of diet, contradictory information could cause a sense of insecurity, hampering attempts to improve their diet.

One moment you can't have an egg, the next you can have three a day, so to speak ... [...]And then this or that is bad, and the other causes cancer [...]It drives me completely nuts.

\section{Limited faith in professional guidance}

Despite the experienced difficulties, participants were sometimes reluctant to seek or accept professional guidance when changing their behaviour. Some had little faith in professional support due to previous, unsuccessful experiences. Others expressed they had no need for support, because they felt their knowledge was already sufficient and feared interference with their own choices.

Yeah but I only went there [dietician] once or twice. That really doesn't work. Well, doesn't work, I mean, you know what to do by yourself

\section{Platform should be easy-to-use}

Although participants were selected on their smartphone possession, they had often limited confidence in their digital skills and foresaw to need detailed instructions and intensive support when introduced to a new app.
If you're going to introduce this [app], you'd really have to educate a group of people, like how do you use something like that?

Other participants expressed that health information and other support from the coach should be easy-to-read, avoiding medical language.

[The app has to be] understandable! Don't go tossing around big words and medical terms and all that.

\section{DISCUSSION}

\section{Summary of main findings}

In this study on attitudes, experiences and views on healthy lifestyles and prevention of CVD and dementia among Dutch low SES older adults, we identified five main themes. First, participants perceived they had limited influence on their future health. Genetic predisposition or faith were considered to be more important determinants of health than own lifestyle behaviours. Second, following a healthier lifestyle was associated with sacrifices on diet or physical exercise that outweighed their potential health benefits, especially with ageing. Third, feedback from the body in terms of illness or physical discomfort could serve as a trigger for behaviour change. Fourth, self-perceived efficacy on behaviour change was limited, especially when previous attempts had been disappointing. Fifth, the social network was of paramount importance to trigger and maintain changes towards healthy behaviours. Finally, provided that the platform is easy-to-use and coach support is trustworthy and presented in a non-obligatory way, mHealth support may be an acceptable and appropriate strategy to facilitate lifestyle behaviour change in low SES older adults who own a smartphone.

\section{Interpretation of findings and comparison with literature}

Our finding that low SES older adults have little confidence that behaviour changes will yield better health outcomes, may be explained by their perceived lack of influence on future health outcomes. A survey on attitudes and beliefs on healthy lifestyles among 2728 adults suggested that low SES individuals less frequently think about the future and foresee a shorter life expectancy than high SES adults. Both characteristics were associated with more unhealthy behaviours, probably reflecting a lack of motivation to change. ${ }^{19}$ In line with our own findings, low SES has been associated with a strong external health locus of control $^{20}$ and strong beliefs in the impact of predestination on health, rather than their own efforts. $^{19}$

Although financial costs, that is, expenses, are a commonly described barrier for healthy behaviours among low SES adults, ${ }^{12} 13$ the notion that costs in a more figurative sense, that is, sacrifices needed to live healthily, outweigh the potential health benefits, appears to be less well-known. In a previous study on perspectives towards 
lifestyle-related secondary CVD prevention, older adults often preferred current quality of life to potential future gains of healthy behaviours, or were only inclined to involve in lifestyle behaviour change when positive effects of these efforts on quality of life were clearly noticeable on the short term. ${ }^{21}$ Other studies described that living healthily comes more easily for those used to healthy behaviours, and vice versa. ${ }^{1322}$ In our study, for many participants healthy diet and regular physical activity were not part of their daily lives. Perhaps, getting more familiar with certain healthy behaviours could partly reduce their negative attitudes.

It has been previously reported that, especially in the lower SES groups, physical impairments or disease onset can prompt behaviour change. ${ }^{132123}$ In our study, also less severe symptoms, such as physical or practical discomfort caused by overweight, rather than disease onset itself, could serve as a trigger.

The expressions of low self-efficacy on behaviour change we observed are in line with several previous studies on low SES and older adults. ${ }^{21} 24-26$ Low self-efficacy usually decreases the chance of successful behaviour change, and unsuccessful attempts further decrease motivation to make renewed attempts. ${ }^{27}$ Although participants in our study were generally not inclined to seek or accept professional support, lifestyle interventions and-support, tailored to their needs and wishes, may have the ability to break this cycle by increasing participants' self-efficacy levels. $^{28} 29$

In line with our own results, previous qualitative studies reported that, regardless of participants' SES, engaging in physical exercise becomes easier and more pleasant when peers are involved. ${ }^{1322}$ A focus group study comparing attitudes towards healthy lifestyles between low and high SES adults reported that low SES adults in particular expressed the need for peers to be of the same age with comparable health complaints. Similarly, regarding nutritional advice, low SES adults had the most outspoken preference for group-oriented approaches. ${ }^{13}$

The Attitudes, Social influence and self-Efficacy (ASE) model is a theoretical framework that aims to explain behavioural intentions ${ }^{30}$ and is based on the Theory of Planned Behaviour. ${ }^{31}$ It suggests that ASE affect behavioural intentions. Personal barriers and skills subsequently affect the transition into actual behaviour. We feel that our results largely fit into the ASE model, as the perceived lack of influence on future health and sacrifices accompanying healthy behaviours represent 'attitudes', the important role for peers represents 'social influence', and the expressions of limited self-confidence clearly link with 'self-efficacy'.

\section{Strengths and limitations}

A main strength of our study is the purposive sample, consisting of older adults who differ in age, living situation, and CVD and diabetes history, contributing to an overview of existing experiences, attitudes and views on healthy lifestyles for disease prevention among low SES older adults in the Netherlands.

A potential limitation of this study is that we only included participants living in the Netherlands. As healthcare systems vary widely in preventive care delivery across countries, applicability of our findings may be limited to low SES populations in countries with similar social services and care provision. Second, general practitioner's were specifically asked to invite low SES individuals, which may have inflated the number of individuals from the lowest SES levels. A final limitation may be that the PRODEMOS intervention was still in the early phase of development when the interviews were performed. The lack of an advanced prototype prohibited an in-depth exploration of specific needs and preferences regarding the functionalities and layout of the mHealth intervention.

\section{Implications for practice}

As self-efficacy levels seemed to be modest at best, low SES older adults may benefit from lifestyle interventions that include human support and aim to increase self-confidence and perceived self-efficacy levels. Appropriateness and attractiveness of such interventions may increase when provided in a non-obligatory way, taking into account the participant's own autonomy. As motives to change tend to focus on concrete, short-term goals rather than prevention of future disease, lifestyle advice should ideally emphasise the direct gains of such changes for daily life. Moreover, lifestyle information for low SES older adults should be easy-to-follow, unambiguous and trustworthy. Given that peer support is an important factor for initiation and sustainability of behaviour change, involving peers may be a valuable approach when developing lifestyle interventions for low SES older adults. As smartphone interventions allow participants to use the intervention in a flexible way, remote coaching using an mHealth application may be a promising strategy to engage low SES adults, provided that it fits their needs, is easy-to-use and comes with extensive and sustained support.

\section{Author affiliations}

${ }^{1}$ Department of General Practice, Amsterdam UMC Locatie AMC, Amsterdam, The Netherlands

${ }^{2}$ Department of Neurology, Amsterdam UMC Locatie AMC, Amsterdam, The Netherlands

${ }^{3}$ Department of Public and Occupational Health, Amsterdam UMC locatie AMC, Amsterdam, The Netherlands

${ }^{4}$ Department of Neurology, Radboud University Donders Institute for Brain Cognition and Behaviour, Nijmegen, The Netherlands

Acknowledgements The authors would like to thank the individuals who agreed to be interviewed for this study, along with the general practitioners and practice nurses who aided recruitment of interview participants. The authors thank Hanneke Muiser for transcription of the interviews.

Collaborators PRODEMOS consortium members: Eric Moll van Charante, Edo Richard, Marieke Hoevenaar-Blom, Esmé Eggink, Melanie Hafdi, Patrick Witvliet (Amsterdam UMC locatie AMC, Amsterdam, the Netherlands). Carol Brayne, Rachael Brooks, Linda Barnes (University of Cambridge, Cambridge, United Kingdom). Wei Wang, Wenzhi Wang, Manshu Song, Jinxia Zhang (Capital Medical University, 
Beijing, China). Anders Wimo, Ron Handels (Karolinska Institutet, Stockholm, Sweden). Sandrine Andrieu, Nicola Coley (INSERMUMR1027,Toulouse, France). Jean Georges, Cindy Birck (Alzheimer Europe, Luxembourg, Luxembourg) Rick Mast (Vital Health Software, Ede, the Netherlands).

Contributors EE was responsible fort the drafting of the manuscript. EE, MH and $\mathrm{MPH}-\mathrm{B}$ conducted the interviews. EE, MH, MPH-B and EPMvC were responsible for coding of the interviews. ER was involved in interpretation of the results, and critically revised the manuscript. All authors approved the final version of the manuscript.

Funding This project has received funding from the European Union's Horizon 2020 Research and Innovation Programme under grant agreement №. 779238 and the National Key R\&D Programme of China (2017YFE0118800).

Competing interests None declared.

Patient consent for publication Not applicable.

Ethics approval This study involves human participants but Medisch Ethische Toetsingscommissie AMC, W19_316 \# 19.374 exempted this study Participants gave informed consent to participate in the study before taking part.

Provenance and peer review Not commissioned; externally peer reviewed.

Data availability statement No data are available. No additional data available.

Supplemental material This content has been supplied by the author(s). It has not been vetted by BMJ Publishing Group Limited (BMJ) and may not have been peer-reviewed. Any opinions or recommendations discussed are solely those of the author(s) and are not endorsed by BMJ. BMJ disclaims all liability and responsibility arising from any reliance placed on the content. Where the content includes any translated material, BMJ does not warrant the accuracy and reliability of the translations (including but not limited to local regulations, clinical guidelines, terminology, drug names and drug dosages), and is not responsible for any error and/or omissions arising from translation and adaptation or otherwise.

Open access This is an open access article distributed in accordance with the Creative Commons Attribution Non Commercial (CC BY-NC 4.0) license, which permits others to distribute, remix, adapt, build upon this work non-commercially, and license their derivative works on different terms, provided the original work is properly cited, appropriate credit is given, any changes made indicated, and the use is non-commercial. See: http://creativecommons.org/licenses/by-nc/4.0/.

ORCID iD

Esmé Eggink http://orcid.org/0000-0001-7132-2937

\section{REFERENCES}

1 de Mestral C, Stringhini S, Status S. Socioeconomic status and cardiovascular disease: an update. Curr Cardiol Rep 2017;19:115.

2 Yaffe K, Falvey C, Harris TB, et al. Effect of socioeconomic disparities on incidence of dementia among biracial older adults: prospective study. BMJ 2013;347:f7051.

3 Laaksonen M, Talala K, Martelin T, et al. Health behaviours as explanations for educational level differences in cardiovascular and all-cause mortality: a follow-up of 60000 men and women over 23 years. Eur J Public Health 2008;18:38-43.

4 Stringhini S, Sabia S, Shipley M, et al. Association of socioeconomic position with health behaviors and mortality. JAMA 2010;303:1159-66.

5 Global digital population as of January 2019. Available: https://www. statista.com/statistics/617136/digital-population-worldwide/

6 Beishuizen CRL, Stephan BCM, van Gool WA, et al. Web-based interventions targeting cardiovascular risk factors in middle-aged and older people: a systematic review and meta-analysis. J Med Internet Res 2016;18:e55.

7 Richard E, Moll van Charante EP, Hoevenaar-Blom MP, et al. Healthy ageing through Internet counselling in the elderly (HATICE): a multinational, randomised controlled trial. Lancet Digit Health 2019;1:e424-34.

8 Eggink E, Hafdi M, Hoevenaar-Blom MP, et al. Prevention of dementia using mobile phone applications (PRODEMOS): protocol for an international randomised controlled trial. BMJ Open 2021;11:e049762.

9 Salmela SM, Vähäsarja KA, Villberg JJ, et al. Perceiving need for lifestyle counseling: findings from Finnish individuals at high risk of type 2 diabetes. Diabetes Care 2012;35:239-41.

10 Hiscock R, Judge K, Bauld L. Social inequalities in quitting smoking: what factors mediate the relationship between socioeconomic position and smoking cessation? J Public Health 2011;33:39-47.

11 Moroshko I, Brennan L, O'Brien P. Predictors of dropout in weight loss interventions: a systematic review of the literature. Obes Rev 2011;12:912-34.

12 Cleland V, Granados A, Crawford D, et al. Effectiveness of interventions to promote physical activity among socioeconomically disadvantaged women: a systematic review and meta-analysis. Obes Rev 2013;14:197-212.

13 Bukman AJ, Teuscher D, Feskens EJM, et al. Perceptions on healthy eating, physical activity and lifestyle advice: opportunities for adapting lifestyle interventions to individuals with low socioeconomic status. BMC Public Health 2014;14:1036.

14 Ball K, Salmon J, Giles-Corti B, et al. How can socio-economic differences in physical activity among women be explained? A qualitative study. Women Health 2006;43:93-113.

15 Noar SM, Benac CN, Harris MS. Does tailoring matter? Meta-analytic review of tailored print health behavior change interventions. Psychol Bull 2007;133:673-93.

16 Brown J, Michie S, Geraghty AWA, et al. Internet-based intervention for smoking cessation (StopAdvisor) in people with low and high socioeconomic status: a randomised controlled trial. Lancet Respir Med 2014;2:997-1006.

17 Coupe N, Cotterill S, Peters S. Tailoring lifestyle interventions to low socio-economic populations: a qualitative study. BMC Public Health 2018;18:967.

18 Braun V, Clarke V. Using thematic analysis in psychology. Qual Res Psychol 2006;3:77-101.

19 Wardle J, Steptoe A. Socioeconomic differences in attitudes and beliefs about healthy lifestyles. J Epidemiol Community Health 2003;57:440-3.

20 Poortinga W, Dunstan FD, Fone DL. Health locus of control beliefs and socio-economic differences in self-rated health. Prev Med 2008;46:374-80.

21 Jepma P, Snaterse M, Du Puy S, et al. Older patients' perspectives toward lifestyle-related secondary cardiovascular prevention after a hospital admission-a qualitative study. Age Ageing 2021;50:936-43.

22 Kamphuis CBM, van Lenthe FJ, Giskes K, et al. Perceived environmental determinants of physical activity and fruit and vegetable consumption among high and low socioeconomic groups in the Netherlands. Health Place 2007;13:493-503.

23 Damiani G, Federico B, Bianchi CBNA, et al. Socio-economic status and prevention of cardiovascular disease in Italy: evidence from a national health survey. Eur J Public Health 2011;21:591-6.

24 Gecas V, Seff MA, Social-Class OC. Social class, occupational conditions, and self-esteem. Sociological Perspectives 1989;32:353-64.

25 Hughes M, Demo DH. Self-Perceptions of black Americans: selfesteem and personal efficacy. Am J Sociol 1989;95:132-59.

26 Boardman JD, Robert SA. Neighborhood socioeconomic status and perceptions of self-efficacy. Sociol Perspect 2000;43:117-36.

27 Grembowski D, Patrick D, Diehr P, et al. Self-efficacy and health behavior among older adults. J Health Soc Behav 1993;34:89-104.

28 Zheng X, Yu H, Qiu X, et al. The effects of a nurse-led lifestyle intervention program on cardiovascular risk, self-efficacy and health promoting behaviours among patients with metabolic syndrome: randomized controlled trial. Int J Nurs Stud 2020;109:103638.

29 Zhang P, Xing F-M, Li C-Z, et al. Effects of a nurse-led transitional care programme on readmission, self-efficacy to implement healthpromoting behaviours, functional status and life quality among Chinese patients with coronary artery disease: a randomised controlled trial. J Clin Nurs 2018;27:969-79.

30 de Vries H, Dijkstra M, Kuhlman P. Self-efficacy: the third factor besides attitude and subjective norm as a predictor of behavioural intentions. Health Educ Res 1988;3:273-82.

31 Ajzen I. From intentions to actions: a theory of planned behaviour. Action Control 1985:11-39. 